\title{
HAFNER AWARD TO DR. JOHN PRICE
}

When we published in News and Notes of the October 1969 issue of Medical History the item about the Hafner Award (p. 393), we did not anticipate that the first award would go to the author of an article in the same issue of our journal. It is therefore with an added pleasure that we report the award of this prize of $\$ 200$ to Dr. John Price for his paper on 'Dominique Anel and the small lachrymal syringe' (Medical History, 1969, 13, 340-354), and we offer Dr. Price our warmest congratulations.

The prize is donated by the Hafner Publishing Company and is sponsored by the American Association for the History of Medicine and the Medical Library Association. It is awarded annually for 'a meritorious article on the history of medicine dealing with a single individual who has made a contribution of historical interest, the article being originally published in the English language during the previous calendar year.'

The presentation was made at the annual meeting of the American Association for the History of Medicine in Birmingham, Alabama, 1-4 April, 1970.

\section{UNIVERSITY OF PENNSYLVANIA}

It is announced that the Rare Book and Conference Room in the new Medical Library of the University of Pennsylvania in Philadelphia will be dedicated in honour of Dr. Richard Harrison Shryock, the distinguished medical historian and bibliographer. A brief, informal dedicatory ceremony was held in the Shryock Room on 17 June.

\section{FLORENCE NIGHTINGALE HOSPITALS AND SCHOOLS OF NURSING, ISTANBUL}

Selimiye Barracks at Scutari, the asiatic part of Istanbul, has been rebuilt to house a School of Higher Nursing Education, a Training Hospital, and a Teaching Health Center in Florence Nightingale's name. Selimiye Barracks was built in 1800, and used as a hospital during the Crimean War. Florence Nightingale and her nurses used the Tower at Selimiye as their living quarters from 1854 to 1856, and laid the foundations of modern nursing in Istanbul. The new Nightingale Centre is a nongovernmental organization planned in 1957 and officially established in 1956. With the co-operation of the Turkish Ministry of Health and Social Welfare, the Centre aims to raise the standard of nursing and public health in Turkey. 